OPEN ACCESS

Edited by:

J. Reinaldo Martínez-Fernández, Universitat Autònoma de Barcelona,

Spain

Reviewed by: Sebastian Bergold,

Technical University Dortmund,

Germany

Tracy X. P. Zou,

The University of Hong Kong, China

*Correspondence:

Dominik E. Froehlich

dominik.froehlich@univie.ac.at

Specialty section:

This article was submitted to

Teacher Education,

a section of the journal

Frontiers in Education

Received: 14 March 2021

Accepted: 05 May 2021

Published: 18 May 2021

Citation:

Froehlich DE, Hobusch U and Moeslinger K (2021) Research Methods in Teacher Education:

Meaningful Engagement

Through Service-Learning.

Front. Educ. 6:680404.

doi: 10.3389/feduc.2021.680404

\section{Research Methods in Teacher Education: Meaningful Engagement Through Service-Learning}

\author{
Dominik E. Froehlich $^{1 *}$, Ulrich Hobusch ${ }^{2}$ and Karoline Moeslinger ${ }^{3}$ \\ ${ }^{1}$ Department of Education and Centre for Teacher Education, University of Vienna, Vienna, Austria, ${ }^{2}$ Ecological Economics \& RCE \\ Vienna, Vienna University of Economics and Business, Vienna, Austria, ${ }^{3}$ Centre for Teacher Education, University of Vienna, \\ Vienna, Austria
}

Competence in research methods is a major contribution to (future) teachers' professionalism. In the pedagogical approach presented here, which we call the Teaching Clinic, we combine service-learning and design-based research to create meaningful learning engagements. We present two cases to illustrate the objectives, processes, and outcomes of the service-learning projects and reflect about both in terms of learning and service outcomes. This includes discussions of how this pedagogical approach led to motivation and engagement, how principles of transfer of training are obeyed, and what this means quite generally for school-university relationships.

Keywords: service-learning, design-based research, research methods, teacher education, engagement

\section{INTRODUCTION}

Research skills, such as the knowledge and skills necessary to pose clear (scientific) questions, to critically review the literature, and to collect, analyze, and interpret data, are important to navigate the complexity of daily life. This is also true for teachers, where research skills and increasingly seen as important elements of professionalism (Amirova et al., 2020) and the establishment of evidencebased teaching practices (Burke et al., 2005). In this article, we aim to present case studies of a pedagogical approach that helps in increasing the perceived relevance of discussing methodological issues within teacher education (Davidson and Palermo, 2015): the Teaching Clinic (TC).

TCs are designed as semester-long courses in which teachers in training (now "students") collaborate with practicing teachers (now "teachers") on pedagogical innovations in the teachers' classrooms through design-based research (Bakker, 2018). They can be seen as instances of service learning in the domain of teacher education (Stoecker, 2016). TCs tackle the combined needs of students, such as the wish for more formal experiences directly in the school-context and obtaining well-transferable competences and knowledge, and teachers, who may want a more direct access to state-of-the-art knowledge and support in implementing pedagogical innovations.

The objective of this article is to present the pedagogical approach taken in the TC and to explore its outcomes in terms of research competence and service through the accounts of stakeholders to the TC. Specifically, we present two exemplary projects that were conducted within the TC and showcase the reflections from students, teachers, and the course facilitators.

\section{CONTEXT AND FRAMEWORKS}

The Teaching Clinic (TC) is a course for Master students in a teacher education curriculum at an Austrian university. Established teachers submit research questions about current professional 
challenges. These questions are then picked up by students, who conceptualize and execute research projects to find evidence based solutions.

The primary objective of doing research at this very local and practical level is to instill a scientific mindset in the students. Research skills are increasingly seen as tools of the professional practice; not as something confined to academic research. Importantly, this perspective is not only shared with the students that work on the projects, but also with the teachers that submit them. In that sense, the TC is about the transfer from university to practice (see also the current debate about "Third Mission"; Schober et al., 2016).

In terms of research methods, two secondary objectives of the format exist. First, the TC presents a clear purpose, and, therefore, motivation, to apply research methods. Second, the students apply research methods in a context that is almost identical to the context of their later work. This facilitates the transfer from the training context to the subsequent professional work as teachers (Blume et al., 2010; Quesada-Pallarès and Gegenfurtner, 2015).

\section{Main Pedagogical Approach: Service-Learning}

The main pedagogical frame used to conduct the TC was servicelearning (Sotelino-Losada et al., 2021). There are numerous definitions of service-learning, but perhaps the most cited is the one formulated by Bringle and Hatcher (1995), who define service-learning as a

“...course-based, credit-bearing educational experience in which students (a) participate in an organized service activity that meets identified community needs and (b) reflect on the service activity in such a way as to gain further understanding of course content, a broader appreciation of the discipline, and an enhanced sense of personal values and civic responsibility" (p. 212).

Service-learning is an experience-based learning approach (Biberhofer and Rammel, 2017) that combines learning objectives with community service and emphasizes individual development and social responsibility through providing a service for others; service situations are viewed as learning settings and opportunities for public engagement (Forman and Wilkinson, 1997). According to Furco (1996), the key lies in the equal benefit for providers (TC: students) and recipients (TC: teachers). The TC could also be discussed from the perspective of transformative learning (Mezirow and Taylor, 2009), as the learning goal of the seminar is not about pure knowledge acquisition, but about "building the capacity of students as agents of change" (Biberhofer and Rammel, 2017, p. 66). The TC provides a rather open learning environment, in which students engage in an open dialogue with each other, with the teachers, and the course facilitator, who does not necessarily possess the necessary subject-matter expertize but provides feedback and guidance throughout this process of dialectic inquiry.

\section{Useful Methodological Lens: Design-Based Research and Action Research}

As stipulated above, the main objective of the TC is to implement research projects at a local level in the teaching context. One methodological perspective that is very well adapted to this aim is design-based research (DBR). DBR is a research approach that claims to overcome "the gap between educational practice and theory, because it aims both at developing theories about domainspecific learning and the means that are designed to support that learning" (Bakker and Van Eerde, 2015, p. 430). In DBR, the design of learning environments proceeds in a reflective and cyclic process simultaneous to the testing or development of theory. The design includes the selection and creation of interventions which is done in cooperation with practitioners, while holding only little control of the situation. This research approach aims to explain and advise on ways of teaching and learning that proved to be useful and to develop theories that can be of predictive nature for educational practice. Because of its interventionist nature, researchers conducting this type of research are often referred to as "didactical engineers" (Anderson and Shattuck, 2012; Bakker and Van Eerde, 2015).

In the TC, we use DBR as a methodological frame to set up the projects. On a micro level, different projects feature very different data (e.g., video recordings, surveys among pupils, interviews, texts, etc.) and methods (e.g., field experiments, statistical analyses, content analysis, etc.). The students need to decide which ones to use, get appropriate data, and run the analysis.

\section{CASES}

\section{Design}

In this section, we present how TCs are a useful context for becoming teachers to develop research competences. Since this is the very first discussion about TCs, we use case studies to explore the outcomes of this pedagogical format. The case studies presented here contain reflections of students, teachers, and course facilitators based on a set of guiding questions in the direction of research methods and service-learning. Specifically, two independent TC projects will be presented. The first project focused on implementing concepts of Education for Sustainable Development (EDS) in the context of socio-economically disadvantaged classes in the field of Science, Mathematics, Engineering, and Technology (STEM). A team of two students and two teachers collaborated to further develop and evaluate lesson plans based on classroom experience, pupils' feedback, and expert knowledge. The second project focused on improving the feedback strategies in response to students' writing in language classrooms. Using an experimental research design, a team of four students generated data to allow for the evidence-based improvement of personal feedback and marking strategies.

Both projects will be reflected from the angles of multiple stakeholders; the team of authors of this article include a Master student, a teacher, and a researcher (and facilitator of the course). This reflects the nature of the TC as a learning experience that is co-created by multiple stakeholders; the participating students 
are not just learners, but also co-researchers and pedagogical codesigners (see Bovill et al., 2016). In the context of this publication students not only helped by providing additional reflections and data (see Case 1), but also by taking the position as a co-author (Case 2 was written by a student of the project; the course facilitator, an experienced researcher and first author of this text, provided feedback but otherwise did not interfere in the writing process; for student faculty-student co-authoring also see Abbott et al., 2021). For each case, we will first describe the objectives as laid out by the submitting teacher(s), the methodological process to find answers to the questions posed, and the final outcomes as reported back to the teacher(s).

\section{Case 1: Education for Sustainable Development for Socio-Economically Disadvantaged Classes in the Prevocational School Sector (Teacher's View)}

This first case about Education for Sustainable Development (ESD) for socio-economically disadvantaged classes in the prevocational school sector is presented from the point of view of the teacher (who submitted the problem to the TC).

\section{Objectives}

The relevance of the global educational environment for social fields of action was already taken up by the United Nations (UN) before the turn of the millennium and led to the years 2005-2014 being declared the World Decade of Education for Sustainable Development (WDESD) (Combes, 2005). In the Germanspeaking countries, the Orientation framework for the learning area "Global Development" serves as an essential contribution to explicit didactics for ESD in the secondary education sector (Schreiber and Siege, 2016).

This pedagogical concept was used by the students to support two teachers at a prevocational school in implementing ESD didactics into Science, Technology, Engineering, and Mathematics (STEM) lessons. The aim of the curriculum was to help low-income pupils at a vulnerable prevocational school location to develop highly demanded competences in the field of STEM professions.

Another objective was to strengthen the students' sense of responsibility for society and environment in alignment with the bottom-up drive of the "FridaysforFuture" movement. The starting point for the research needs in schools was a study conducted by the German Federal Environment Agency, which asked whether environmental protection as a motive is useful for addressing young people's motivation to enter STEM professions more successfully than before (Örtl, 2017). The results of the study imply, among other aspects, that STEM didactics have close links to ESD and that synergetic overlaps in this area seem to be a promising approach for STEM lessons at prevocational schools.

\section{Process}

Throughout the TC, promising learning formats in STEM lessons were tested in iterative cycles of implementation, evaluation, and adjustment in the sense of DBR at the chosen school site. Here, learning journals produced by students for different learning formats in STEM lessons on the topic "Renewable Energies" and "Climate Change" served as the primary data to create a scientifically and empirically driven curriculum for motivating students to pursue STEM professions (see Figure 1).

The method of structured qualitative content analysis (Mayring, 2014) was used to search for indicators that make learning formats subjectively interesting for students. The students were required to document steps and problems that occurred during the implementation and evaluate the learning opportunities on an ordinal scale from one to five after completion of the learning journal. The underlying learning formats include problem-centered films, concrete technical tasks (programming, mechanics, construction, electronics, and applied computer science), external workshops and lectures with companies from the technology sector.

After an initial review of the data, implications for the indicator "perceived as subjectively interesting by the students" could be concluded. The finding showed that individual isolated learning opportunities on the topic of climate change do not necessarily lead to the desired effect of students showing intrinsic motivation to acquire relevant professional skills for finding solutions.

Based on these interim results, the TC students consulted the scientific literature, which allowed for contextualization of socially relevant and scientific-technical dimensions in the acquisition of competencies in the sense of ESD. The framework for this approach was provided by the German Federal Ministry for Economic Cooperation and Development (BWZ) and the German Conference of Ministers of Education and Cultural Affairs (KMK) (Schreiber and Siege, 2016).

Through the continuous cycles of the DBR approach using different learning formats in ongoing school lessons, the students were able to develop a hybrid ESD/STEM curriculum step by step by evaluating the data material. Decisive input for the concrete lesson plans was derived from the indicators identified through the structured content analysis according to Mayring (2014), which were perceived by the students as subjectively interesting and motivating. Due to COVID-19-related school closures, it was not possible to complete an annual curriculum. Nevertheless, a total of 16 lessons that met the requirements of the research assignment based on the identified indicators were designed. The curriculum created through the cooperation of school and TC now serves as a preliminary study and basis for a fully empirical main study, which is to be carried out at several school locations after the worldwide COVID-19 pandemic. The results of the qualitative preliminary study were used by the students in the final step to formulate hypotheses for the main study in accordance with the underlying research question following Mayring (2014) methodological approach.

\section{Outcomes}

In addition to the general results of the qualitative preliminary study, various positive effects on the stakeholders could be identified in the present case as a result of the service-learning offering. The question chosen in the case study whether environmental protection issues can contextually contribute to motivating young people in STEM classes to take an interest in 


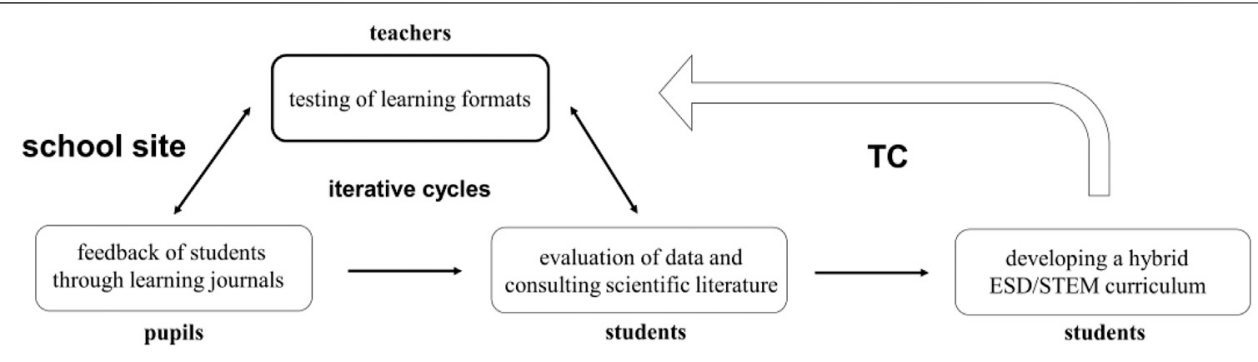

FIGURE 1 | Overview over the work process in Case 1.

related professions could not be fully answered. However, the DBR approach has served to identify those indicators based on different learning formats that were rated as subjectively interesting and motivating for students. As a pedagogical and didactic core concept, the approach of the "Recognize- Evaluate- Act"-principle from the Orientation framework for the learning area "Global Development" (Schreiber and Siege, 2015) turned out to be particularly promising. Furthermore, a concrete further research assignment for the TC could be derived from the results to initiate a fully comprehensive empirical study based on pre-formulated hypotheses.

The TC research semester was described by the students as an eye-opening experience between university teaching and practical school experience. In this case, the service-learning project enabled the Master students to implement theoretically learned scientific methods in a practical way within the school environment. The scholarly exposure to ESD content along with instructional development using STEM learning opportunities gave the Master students a holistic view into practice-based teaching and learning research.

"The exchange, especially the feedback, with teaching staff at a preparatory vocational school with difficult socio-economic conditions was far more informative and practically relevant to me than most frontal lectures at the university. In addition to the practical and schoolrelevant part of the research semester, the TC together with ESD principles was an enriching support for me to be able to conduct current educationally relevant research in a scientifically and methodologically correct way. The balance between the cornerstones of school practice, TC and the final research work has given me a new perspective and understanding of the profession of a teacher and the different places of work." (Student)

Furthermore, the underlying DBR approach has been identified as a promising approach for adapting hybrid ESDSTEM learning formats and teaching contents to determine successful learning effects with students.

The service-learning concept offered freed up additional resources for instructional development that would have been difficult to implement during the regular school year due to administrative duties and other teacher commitments. This gave teachers the opportunity not only to get ideas for lesson design, but also to further develop their own teaching based on sound and up-to-date scientific methodology. Learnings reportedly included new ways "to inspire the students with new approaches and to show them that STEM cannot be purely theoretical, but that it is important for them and society."

Through the joint development of the curriculum, it was possible to link subject-related STEM lessons with social relevance, which often seems intangible for students, especially in STEM subjects. Teachers attributed great importance to this interconnection in identifying students' ability to explore, reflect, and critically evaluate scientific content from multiple perspectives.

"Experiencing values such as sustainability, environmental awareness and solidarity [...] provide a good basis for developing into independent and responsible personalities." (Teacher)

Particularly the context of teaching at a socially vulnerable school site suggests a value-oriented attitude and precise concept of learning formats next to topics that are relevant to the realities of the young people's lives.

The composition of the student body in the underlying prevocational preparation school class showed a high degree of heterogeneity in terms of country of origin and socioeconomic status. $90 \%$ of the students had a first language other than German and the vast majority could be classified as belonging to a deprivileged class of the population. The empowerment of being able to work on a curriculum for their future career led to increased motivation for the lessons, which could be seen in the underlying learning journals. The motivation was also reflected in an increased learning curve in STEM-related subject knowledge. Moreover, students' involvement with environmental and social issues of the 21 st century led to an observable increased interest in technical and scientific career profiles.

\section{Case 2: Effective Feedback (Student's View)}

The second case shall illustrate the student's perspective and is written by a student of the TC. The project had been carried out in the summer term 2020 and was conducted by a team of four students. The collaboration took place in a school in Vienna with two teachers and two lower-secondary classes of theirs. 

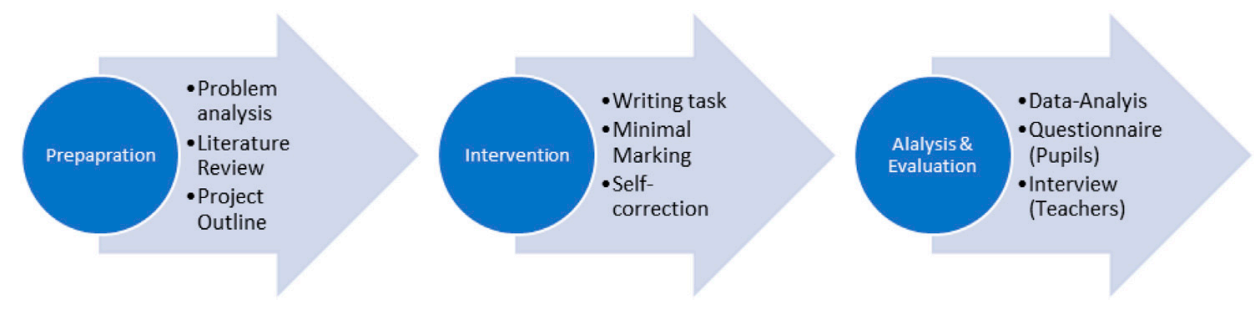

FIGURE 2 | Experimental setup of case 2.

\section{Objectives}

At the beginning of the TC, we were confronted with a common problem of teachers: An English and a German teacher reported that they spend much time correcting their pupils' assignments while suspecting that their pupils did not use the feedback for their own progress. In close exchange with the teachers and after an initial evaluation of the problem, we formulated a project goal: an invention should be set to counteract this problem and improve the situation for both learners and teachers.

\section{Process}

As a first step, a thorough literature review was necessary to find appropriate strategies to tackle the problem. There exists a plethora of publications about feedback strategies; to narrow down our focus, we opted for the "minimal marking" approach because this strategy directly addresses both issues voiced by the teachers. As Hyland (1990) puts it very precisely:

Many teachers find marking to be a tedious and unrewarding chore. While it is a crucial aspect of the classroom writing process, our diligent attention and careful comments only rarely seem to bring about improvements in subsequent work (p. 279).

Besides Hyland (1990), also Haswell (1983) dedicated a publication to the same issue. Both suggested minimal marking as a solution to reduce the teacher's workload by simultaneously increasing the positive effect of the feedback. The basic principle of minimal marking is that instead of detailed feedback, only a cross or a check is set beside the line in which the mistake occurred; subsequently, it is the pupil's task to correct his/her own text by identifying the mistakes and correcting it using prior knowledge or a dictionary (p. 600). Thus, the pupil receives as minimal information as necessary and is encouraged to edit the text independently (Haswell, 1983, p. 601). Through this approach, pupils shall be enabled to edit their texts without much support of the teacher or other adults, which shall help them to develop essential writing skills. This method is considered especially effective because it requires the pupil to act on the feedback received by the teacher (Hyland, 1990, p. 279). Although this approach is still applied nowadays (McNeilly, 2014), it has received little attention in research. Due to this research gap and our personal interest in the topic as future language teachers, we ventured out to explore the effects of minimal marking on (a) learner's mistake awareness, (b) the time teachers spend on giving feedback and (c) the quality as perceived by pupils and teachers.

To answer these research questions, we chose a set of methods consisting of quantitative and qualitative tools (see Figure 2). The procedure can be described as the following: Pupils of both classes were divided in an experimental group and a control group. Then all pupils of one class were asked to write a text in response to the same task. Teachers gave feedback using their traditional method, in which they indicate every mistake and write a short comment to each one, among the control group and using the minimal marking strategy to give feedback on the texts of the experimental group. Both teachers measured the time they needed to correct every single text. Then the pupils got their texts back and edited them. Then the edited texts were collected again. Discovered and undiscovered mistakes were counted and analyzed in the texts of both groups. Time spent on correction was analyzed for each group and juxtaposed. The pupils were asked for their opinion after the experiment through an online survey which consisted of closed and open questions. Finally, the teachers shared their experience in a narrative interview, which was also conducted online.

\section{Outcomes}

Although the results of this small-scale study were not statistically significant, some interesting insights could be gained. Although an increased mistake awareness among pupils could not be proved with the number of mistakes occurring in the first and second text, an increased mistake awareness can be inferred from the pupil's answers given in the questionnaire. Several pupils highlighted the positive aspects of the minimal marking approach and considered it as (really) helpful; one of the learners summarized: "I thought more about my mistakes than I usually do and, hence, I could improve my writing skills. It was more difficult to find the mistakes, but it also helped me to get better" (translated by the authors).

Regarding the time spent for correction, an advantage of the minimal marking approach could only be detected in one of both classes. The German teacher reported an average correction time of 3:14 (first round) and 2:12 (second round) per text using the traditional method and an average time of 1:39 (first round) and 1:14 (second round) per text using the minimal marking approach. The English teacher measured similar times for both feedback strategies. Limiting factors, such as the small sample size of the project and the pupils' unfamiliarity with the new method, need to be kept in mind when conclusions are 
drawn. However, this only highlights the need for further research about the effects of this specific feedback method.

Probably the most promising outcomes can be reported about the attitudes of teachers and pupils. Both teachers described the collaboration between them and the students as enriching and both want to continue the collaboration with the university. Additionally, they reported an increased interest in action research for themselves but also among their colleagues. Through the questionnaire we could also observe a positive attitude toward the experiment among pupils, which gives reason for further projects in class and to further incorporate pupils in research. And finally, we students were able to develop a deeper understanding of teacher professionalism and a more positive attitude toward the application of research in teaching. Additionally, all members of the team were convinced that they wanted to apply this method as teachers in their future practice.

\section{DISCUSSION}

As outlined above, the objectives of the pedagogical/didactical concept of the TC are to create a highly effective (co-creative) learning environment for teachers in training while at the same time delivering valuable service to practice.

\section{Reflections on Learning}

Several themes of learning emerged in the cases above. The opportunity to combine own learning with delivering a service was described as important. Being of service to someone matters and enhances the motivation of students to engage also with the methodological parts of the course. The ESD case confirms the findings of Biberhofer and Rammel (2017) derived in the context of their two-semester "Sustainability Challenge", which has been successfully executed since 2010. Participation in real life problems increases intrinsic motivation to investigate solutions (and to apply the methods needed to carry out this investigation). The master students who carried out the minimal marking project pointed out that this collaboration enabled them to apply research methods in an authentic environment and, thus, rendered them more meaningful. Additionally, this project allowed them to engage with research methods in a demanding but motivating manner which is a frequently neglected part in teacher education. The project enabled them to practice teaching methods and evaluate them through scientific methods in a systematic way; this led to a better understanding of the vital symbiosis between research and practical teaching (Paran, 2017). The exploratory case studies presented in this paper cannot give an in-depth account of the learnings processes and outcomes. Future research could seek to further explore the impact of service-learning approaches to the students' motivation (cf. Medina and Gordon, 2014; Huber, 2015).

There are some indications that the course had a positive impact on the students' future professionalism as teachers and their scientific attitude. In the ESD case, students' engagement with the dimensions of ecological and social justice (which are integral components of ESD) was evident primarily at two levels. On the one hand, the professional engagement with ESD led to the desire to make its impact on students measurable through scientific methodologies. On the other hand, a reframing in the sense of transformative learning (Mezirow and Taylor, 2009) about the subjective role perception as a teacher for shaping an sustainable worldview for future generations of pupils could be observed. The master students of the minimal marking project considered the collaboration with already practicing teachers as especially helpful. Firstly, this special constellation allowed them to gain practical experience besides the obligatory practicum and benefit from the teachers' experience. Secondly, the conduction within the university context required them to combine academic research and practical teaching. This supported them in their professional development as teachers because it made them realize the importance of research methods in evidence-based teaching (Paran, 2017).

Basically, having learned and experienced how to utilize research methods not just for the purpose of "pure research", but framing it as a practice of evidence-based teaching, is expected to make teachers perform better in an increasingly VUCA (volatile, uncertain, complex, and ambiguous; Johansen and Euchner, 2013; LeBlanc, 2018) world. The COVID-19 pandemic is a case in point here. While all teachers needed to react to the changing context, not all did so in a thoughtful and effective manner (Hodges et al., 2020). Different levels of professionalism and of having a scientific mindset could be a major factor in this equation. As described above, increasing this mindset was the primary objective of the course format and we hypothesize that this is an important ingredient to foster teachers' lifelong learning (Bakkenes et al., 2010; Hoekstra and Korthagen, 2011).

An important strategy to increase the learning outcomes for students used in the TC is to work directly in the context that the knowledge should later be applied in. Put differently, the Master students support one individual overcoming a teaching-related challenge. This similarity of contexts aids the transfer of the learnings and helps to make them more applicable (Blume et al., 2010; Burns, 2008). Additionally, the learning process is highly social, including peers, the course facilitator(s), and the teachers. Previous research indicates that this social dimension may additionally increase the odds of "successful" learning (Daniel et al., 2013; Penuel et al., 2012). In the ESD case, confirmation of the success of the underlying ESD/STEM concept for increasing young people's enthusiasm for STEM careers was a transformational realization for the teachers and master's students in the collaborative learning process. Similarly, the minimal marking group reported an unprecedented feeling of responsibility in comparison with other university courses. Because of the knowledge that their collaborating teachers and their students profited from the project, the students' work felt meaningful and important. Simultaneously, this environment enabled them to gain experience in research methods and practical teaching which would not be possible without this unique course format.

On the other hand, students gained practical experience in non-university organizations during their studies. In the feedback, the students commented on both, gaining experience from the school context in cooperation with the teachers and the 
methodological and research-oriented support by the TC itself. The work at local school sites additionally motivates the students to further develop their pedagogical and didactic knowledge in a practical setting based on current school challenges. Furthermore, the interaction of the scientific approach together with the practical school experiences enables the students to internalize their own values for contemporary teaching for their future role as teachers themselves.

\section{Reflections on Service}

The teachers involved in the projects described above reported high satisfaction with the project results and an increased interest in research even extending to their colleagues. Teachers valued the opportunity to develop and improve their teaching formats and methods based on evidence and through scientific methods. Through the collaboration with students, time-consuming research could be outsourced, and the desired role of the teacher researcher could be fulfilled despite time constraints.

As shown in Figure 1 of the ESD case, the clear division of roles with clear lines of communication and distributions of action items was a major advantage in the creation and implementation of the ESD/STEM curriculum. The wellstructured method of the DBR approach throughout the semester allowed for proper planning at each point in time for the scarce time resources of the various stakeholders involved during the school year. The teachers engaged in the minimal marking project also reported an increased interest in research and collaboration with the university which further extended among their colleagues. At the end of the project, they expressed their wish to continue collaboration with students of next courses to further improve their teaching. This illustrates the positive influence on the teachers' attitude toward research and even a potential multiplying factor of the teaching clinic on teachers beyond the active participants.

Finally, the TC can function as a promising channel to maintain communication between teachers and research (Paran, 2017). The collaboration between teachers working in the field and university may lead to the identification of new research gaps on the one side and more evidence-based teaching on the other. Introducing teachers to the concept of evidence-based teaching in early stages of their education may have a positive effect on their attitude toward research in teaching and be the key to the development of a professional role teacher as researcher (Paran, 2017). This illustrates the close interconnections between research at university, teacher education and practicing teachers and their potential to profit from collaboration with each other.

\section{REFERENCES}

Abbott, L., Andes, A., Pattani, A., and Mabrouk, P. A. (2021). An Authorship Partnership with Undergraduates Studying Authorship in Undergraduate Research Experiences. Teaching and Learning Together in Higher Education 1 (32).

Amirova, A., Iskakovna, J. M., Zakaryanovna, T. G., Nurmakhanovna, Z. T., and Elmira, U. (2020). Creative and research competence as a factor of professional training of future teachers: Perspective of learning technology. Wjet 12 (4), 278-289. doi:10.18844/wjet.v12i4.5181

\section{Other Outcomes}

The TC aims to create value in terms of enhancing university social responsibility (Vasilescu et al., 2010). Universities play an important role in addressing global challenges, such as growing socio-economic differences, the climate crisis, or the current COVID-19 pandemic. Irrespective of the specific disciplines, the concept of university social responsibility suggests that universities should not limit themselves to research and teaching, but should commit to solving economic, social, and ecological problems. Universities play a central role in raising students' awareness of social responsibility to help them develop into social personalities (Bokhari, 2017). In that sense, special attention must be paid to teacher education for its promise of achieving multiplication effects that will eventually reach all educational levels. The principle of "Third Mission" provides a key point of reference in this context, which emphasizes the targeted use of scientific findings to deal with a wide range of societal challenges and proposes the transfer of technologies and innovations to nonacademic institutions (Schober et al., 2016).

The systematic approach at hand uses a university research service to address concrete issues in the local field of schooling. The benefit lies in the possibility of merging education theory with socially relevant topics from multiple perspectives. The TC initiates a sustainable circular process, which facilitates the generation of a mutual learning curve for the university system and the school system by instrumentalizing research on an evidence-based level. Thereby, the TC acts as a door opener for practice researchers with access to the otherwise difficult to access compulsory school system.

\section{DATA AVAILABILITY STATEMENT}

The original contributions presented in the study are included in the article/Supplementary Material, further inquiries can be directed to the corresponding author.

\section{AUTHOR CONTRIBUTIONS}

DF designed the didactical concept and has written the conceptual part of this article. UH and KM were stakeholders to the two case studies presented in the article. Both have collected data for their case-study and offered their own reflections. All authors contributed to the overall discussion.

Anderson, T., and Shattuck, J. (2012). Design-Based Research. Educ. Res. 41 (1), 16-25. doi:10.3102/0013189X11428813

Bakkenes, I., Vermunt, J. D., and Wubbels, T. (2010). Teacher learning in the context of educational innovation: Learning activities and learning outcomes of experienced teachers. Learn. Instruct. 20 (6), 533-548. doi:10.1016/j. learninstruc.2009.09.001

Bakker, A. (2018). Design research in education: A practical guide for early career researchers. Abingdon, UK: Routledge. doi:10.4324/9780203701010

Bakker, A., and Van Eerde, D. (2015). "An introduction to design-based research with an example from statistics education", in Approaches to qualitative 
research in mathematics education. Springer, 429-466. doi:10.1007/978-94017-9181-6_16

Biberhofer, P., and Rammel, C. (2017). Transdisciplinary learning and teaching as answers to urban sustainability challenges. Ijshe 18 (1), 63-83. doi:10.1108/ IJSHE-04-2015-0078

Blume, B. D., Ford, J. K., Baldwin, T. T., and Huang, J. L. (2010). Transfer of Training: A Meta-Analytic Review. J. Manag. 36 (4), 1065-1105. doi:10.1177/ 0149206309352880

Bokhari, A. A. H. (2017). Universities" Social Responsibility (USR) and Sustainable Development: A Conceptual Framework. Ijems 4 (12), 8-16. doi:10.14445/ 23939125/IJEMS-V4I12P102

Bovill, C., Cook-Sather, A., Felten, P., Millard, L., and Moore-Cherry, N. (2016). Addressing potential challenges in co-creating learning and teaching: overcoming resistance, navigating institutional norms and ensuring inclusivity in student-staff partnerships. High Educ. 71 (2), 195-208. doi:10. 1007/s10734-015-9896-4

Bringle, R. G., and Hatcher, J. A. (1995). A Service-Learning Curriculum for Faculty. Michigan Journal of Community Service Learning 2 (1), 112-122.

Burke, L. E., Schlenk, E. A., Sereika, S. M., Cohen, S. M., Happ, M. B., and Dorman, J. S. (2005). Developing research competence to support evidence-based practice. J. Professional Nursing 21 (6), 358-363. doi:10.1016/j.profnurs.2005.10.011

Burns, J. Z. (2008). Informal learning and transfer of learning: How new trade and industrial teachers perceive their professional growth and development. Career Techn. Educ. Res. 33, 3-24. doi:10.5328/cter33.1.3

Combes, B. P. Y. (2005). The United Nations Decade of Education for Sustainable Development (2005-2014): Learning to Live Together Sustainably. Appl. Environ. Educ. Commun. 4 (3), 215-219. doi:10.1080/15330150591004571

Daniel, G. R., Auhl, G., and Hastings, W. (2013). Collaborative feedback and reflection for professional growth: Preparing first-year pre-service teachers for participation in the community of practice. Asia-Pac. J. Teacher Educ. 41 (2), 159-172. doi:10.1080/1359866X.2013.777025

Davidson, Z. E., and Palermo, C. (2015). Developing Research Competence in Undergraduate Students through Hands on Learning. J. Biomed. Educ. 2015, 1-9. doi:10.1155/2015/306380

Forman, S. G., and Wilkinson, L. C. (1997). Educational policy through service learning: Preparation for citizenship and civic participation. Innov. High Educ. 21 (4), 275-286. doi:10.1007/BF01192276

Furco, A. (1996). Service-Learning: A balanced approach to experiential education, 7

Haswell, R. H. (1983). Minimal Marking. College English 45 (6), 600-604. doi:10. $2307 / 377147$

Hodges, C., Moore, S., Lockee, B., Trust, T., and Bond, A. (2020). The Difference Between Emergency Remote Teaching and Online Learning. EDUCAUSE Quarterly 15.

Hoekstra, A., and Korthagen, F. (2011). Teacher Learning in a Context of Educational Change: Informal Learning Versus Systematically Supported Learning. J. Teacher Educ. 62 (1), 76-92. doi:10.1177/0022487110382917

Huber, A. M. (2015). Diminishing the Dread: Exploring service learning and student motivation. Ijdl 6 (1). doi:10.14434/ijdl.v6i1.13364

Hyland, K. (1990). Providing productive feedback. ELT J. 44 (4), 279-285. doi:10. 1093/elt/44.4.279

Johansen, B., and Euchner, J. (2013). Navigating the VUCA World. Res.-Technol. Manag. 56 (1), 10-15. doi:10.5437/08956308X5601003
LeBlanc, P. J. (2018). Higher Education in a VUCA World. Change Magazine Higher Learn. 50 (3-4), 23-26. doi:10.1080/00091383.2018.1507370

Mayring, P. (2014). Qualitative content analysis. doi:10.4135/9781446282243

McNeilly, A. (2014). Minimal Marking: A Success Story. cjsotl-rcacea 5 (1). doi:10. 5206/cjsotl-rcacea.2014.1.7

Medina, A., and Gordon, L. (2014). Service Learning, Phonemic Perception, and Learner Motivation: A Quantitative Study. Foreign Language Annals 47 (2), 357-371. doi:10.1111/flan.12086

Mezirow, J., and Taylor, E. W. (2009). Transformative learning in practice: Insights from community, workplace, and higher education. John Wiley \& Sons.

Örtl, E. (2017). MINT the gap - Umweltschutz als Motivation für technische Berufsbiographien? Umweltbundesamt. https://www.umweltbundesamt.de/ publikationen/mint-the-gap-umweltschutz-als-motivation-fuer

Paran, A. (2017). 'Only connect': researchers and teachers in dialogue. ELT J. 71 (4), 499-508. doi:10.1093/elt/ccx033

Penuel, W. R., Sun, M., Frank, K. A., and Gallagher, H. A. (2012). Using social network analysis to study how collegial interactions can augment teacher learning from external professional development. Am. J. Educ. 119 (1), 103-136. doi:10.1086/667756

Quesada-Pallarès, C., and Gegenfurtner, A. (2015). Toward a unified model of motivation for training transfer: A phase perspective. Zeitschrift Für Erziehungswissenschaft 18 (S1), 107-121. doi:10.1007/s11618-014-0604-4

Schober, B., Brandt, L., Kollmayer, M., and Spiel, C. (2016). Overcoming the ivory tower: Transfer and societal responsibility as crucial aspects of the BildungPsychology approach. Eur. J. Dev. Psychol. 13 (6), 636-651. doi:10.1080/ 17405629.2016.1231061

J.-R. Schreiber and H. Siege (2015). Orientierungsrahmen für den Lernbereich Globale Entwicklung [rientation Framework for the Learning Area Global Development, p. 468.

J.-R. Schreiber and H. Siege (2015). in Curriculum Framework: Education for Sustainable Development. Engagement Global gGmbH. 2nd edn.

Sotelino-Losada, A., Arbués-Radigales, E., García-Docampo, L., and GonzálezGeraldo, J. L. (2021). Service-Learning in Europe. Dimensions and Understanding From Academic Publication. Front. Educ. 6. doi:10.3389/ feduc.2021.604825

Stoecker, R. (2016). Liberating service learning and the rest of higher education civic engagement. Philadelphia, PA: Temple University Press.

Vasilescu, R., Barna, C., Epure, M., and Baicu, C. (2010). Developing university social responsibility: A model for the challenges of the new civil society. Proc. Soc. Behav. Sci. 2 (2), 4177-4182. doi:10.1016/j.sbspro. 2010.03.660

Conflict of Interest: The authors declare that the research was conducted in the absence of any commercial or financial relationships that could be construed as a potential conflict of interest.

Copyright $\odot 2021$ Froehlich, Hobusch and Moeslinger. This is an open-access article distributed under the terms of the Creative Commons Attribution License (CC BY). The use, distribution or reproduction in other forums is permitted, provided the original author(s) and the copyright owner(s) are credited and that the original publication in this journal is cited, in accordance with accepted academic practice. No use, distribution or reproduction is permitted which does not comply with these terms. 